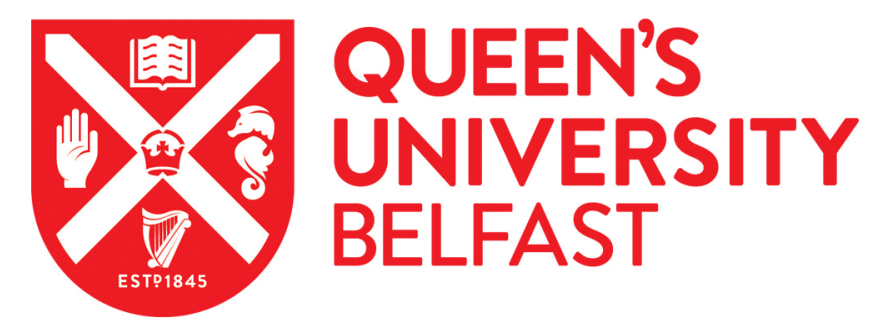

\title{
Picturing Probation: Exploring the utility of visual methods in comparative research
}

Carr, N., Bauwens, A., Bosker, J., Donker, A., Robinson, G., Sucic, I., \& Worrall, A. (2015). Picturing Probation: Exploring the utility of visual methods in comparative research. European Journal of Probation, 7(3), 179-200. https://doi.org/10.1177/2066220315617269

Published in:

European Journal of Probation

Document Version:

Peer reviewed version

Queen's University Belfast - Research Portal:

Link to publication record in Queen's University Belfast Research Portal

Publisher rights

(C) The Author(s) 2015

Reprints and permissions: sagepub.co.uk/journalsPermissions.nav

\section{General rights}

Copyright for the publications made accessible via the Queen's University Belfast Research Portal is retained by the author(s) and / or other copyright owners and it is a condition of accessing these publications that users recognise and abide by the legal requirements associated with these rights.

Take down policy

The Research Portal is Queen's institutional repository that provides access to Queen's research output. Every effort has been made to ensure that content in the Research Portal does not infringe any person's rights, or applicable UK laws. If you discover content in the Research Portal that you believe breaches copyright or violates any law, please contact openaccess@qub.ac.uk. 
Picturing Probation: Exploring the utility of visual methods in comparative research.

Authors:

Carr, N.; Bauwens, A.; Bosker, J.; Donker, A.; Robinson, G., Sucic, I. \& Worrall, A.

Abstract

A previous review of research on the practice of offender supervision identified the predominant use of interview-based methodologies and limited use of other research approaches (Robinson and Svensson, 2013). It also found that most research has tended to be locally focussed (i.e. limited to one jurisdiction) with very few comparative studies. This article reports on the application of a visual method in a small-scale comparative study. Practitioners in five European countries participated and took photographs of the places and spaces where offender supervision occurs. The aims of the study were two-fold: firstly to explore the utility of a visual approach in a comparative context; and secondly to provide an initial visual account of the environment in which offender supervision takes place. In this article we address the first of these aims. We describe the application of the method in some depth before addressing its strengths and weaknesses. We conclude that visual methods provide a useful tool for capturing data about the environments in which offender supervision takes place and potentially provide a basis for more normative explorations about the practices of offender supervision in comparative contexts.

Keywords: Comparative Research; Visual Methods; Photo-voice; Auto-elicitation; Workspace

\section{Introduction}

The use of visual research methods has grown in popularity in recent years prompted by wider and easier access to technology and a move towards interpretivist research approaches (Harper, 2002; Stanczak, 2007; Ray \& Smith, 2012). Similarly within criminological research attention towards visual iconography and visual methods is gaining wider currency (Rafter, 2014). The concept of 'visual criminology' is an umbrella term that covers the production, encounter and analysis of a range of images - fine art, film, media and photography (Brown and Carrabine, forthcoming). In this article, we focus on the photograph and specifically on photographs taken by probation officers of the physical environment in which they 
work in a number of European countries. We discuss the process whereby we have attempted to adapt the concept of 'still life' photography (that is, photography of places and objects) to the mundane process of practising the community supervision of offenders. We have done this through, first, the democratization of photo-taking (Carrabine, 2012) and, second, comparative photo-taking across several European countries.

Much of the existing literature on photography in criminology has been written by 'cultural criminologists' (Hayward and Presdee 2010) who argue, amongst other things, that mainstream criminology is in crisis because it is 'ill-equipped to critically engage with the image-saturated worlds of crime and control' (Ferrell and Van de Voorde, 2010:48). Arguments about the creation of photographs, especially by professional journalists and especially relating to policing and public order, and about their interpretation, abound. Similarly, the visual depiction of individual criminals and their victims features widely. And while criminology can be said to be experiencing a 'visual turn' (Rafter, 2014), evident in the gaze directed towards crime and the institutions of crime control, perhaps unsurprisingly within the emergent field of visual criminology, community sanctions and measures have garnered relatively limited attention. This mirrors their wider neglect in penal scholarship (McNeill and Beyens, 2013).

Bearing in mind the relative invisibility of probation and community sanctions when compared with other forms of punishment (Robinson, forthcoming), the aims of this small scale study were two-fold. Firstly, we wanted to explore the utility of a visual approach within a comparative context and, secondly, we sought to provide an initial visual account of the environment in which offender supervision is experienced and practiced. This article addresses the first of these aims, i.e. the methodological aspects of the study. In it we focus specifically on the use of the method, with a particular emphasis on its utility and feasibility in comparative research. We begin by describing the methodology in some depth, before proceeding to address its strengths and limitations. We conclude with a discussion prompted by a consideration of the challenges of comparability and of the questions raised by what we see. 


\section{Visual Methods and Comparative Research}

A previous review of research on the practice of offender supervision identified the predominant use of interview-based methdologies and limited use of other research approaches (Robinson and Svensson, 2013). Most research has tended to be locally focussed (i.e. limited to one jurisdiction) with very few comparative studies. With this in mind, this small-scale study involving participants in the COST Action ${ }^{1}$ on Offender Supervision in Europe's Working Group on Practising Supervision aimed to explore the utility of a visual methodology, both to shed light on the practice of offender supervision and as a comparative research approach. Here we provide an account of our application of this method by situating our discussion within wider literature on visual research approaches and some of the challenges of comparative research.

The decision to use a visual research approach was grounded in an intuitive belief that images would potentially bring the field of offender supervision into view, or at least open up a window into practice. This sense that visual images may reveal more about practice than words alone, or perhaps more acccurately than individuals' accounts of their practice retold to a researcher, was supported by literature on the use of visual approaches in a variety of settings (Prosser and Schwartz, 1998, Kanstrup, 2002; Rose, 2007; Ray and Smith 2012). This literature highlighted some of the potential benefits of visual methods. Not all knowledge is reducible to language or may be easily expressed in words and therefore visual methods may allow us access to new information (Eisner, 2008; Bagnoli, 2009). Visual data may show us things that we would not have thought to ask about or may not have considered to be important. They can also generate rich data incorporating a mutliplicity of perspectives (Prosser and Schwartz, 1998; Bagnoli and Clark, 2010).

The democratisation of technology and the proliferation of tools through which images can be generated (smartphones, digitial cameras, etc.) has further opened up the possibilities for visual research (Rose, 2007; Stanczak, 2007). Increased accessibility has brought greater familiarity and technological innovations have

\footnotetext{
${ }^{1}$ See www.offendersupervision.eu
} 
meant that devices are relatively easy to use. Digitisation has also meant that there are limited costs involved in generating and sharing images. Depending on the particular approach taken, other benefits include the potential empowerment of research participants by promoting co-creation, reflexivity and engagement in the research process (Prosser and Schwartz, 1998; Kanstrup, 2002; Rose, 2007).

For the purposes of comparative research, visual methods offer the potential to overcome some of the challenges involved in comparing practice across different countries and languages (Nelken, 2012; Pakes, 2014). Here the possibility of a picture 'speaking a thousand words' seemed to us to provide a window through which we could explore different cultures and practices of offender supervision. However, all of this suggests a certain seductive simplicty, which visual researchers caution against (Rose, 2007). For one thing, images are the result of the observer's multiple mechanisms of meaning and selection. Secondly, visual signifiers are subjective and so the 'thousand words' analogy may depend on who is looking and what interpretations they are drawing (Gilbert, 2008; Knoblauch et al, 2008; Prosser and Loxley, 2008). Bearing all of this in mind, the next section sets out the partiular approach undertaken in this small-scale study of using visual methods in a comparative context.

\section{About the study}

The study took place between February and July 2014. Seven researchers from five European countries - Belgium, Croatia, the Netherlands, Northern Ireland, and England - participated. All of the researchers in the group had previous experience of research in the field of offender supervision. Although the networking activities of the COST Action are funded, no funding is available for empirical research. Therefore there were no funds available for data collection. Having decided to pilot a visual methodology to research offender supervision in a comparative context, the first consideration was to decide what aspects of offender supervision could be explored using this method. Following some consideration, we decided to use the method to primarily explore the materiality of probation contexts; that is, the physical environment in which offender supervision takes place. 
The decision to focus on the environments of probation practice was based on the view that material surroundings have the potential to shape interactions but also communicate something about the manner in which both offender supervision and offenders are viewed. An emergent body of criminological research exploring the 'spaces and places' of incarceration under the banner of 'carceral geography' (see Moran, 2015), has directed attention to the importance of 'emotional geographies' in shaping prison life (see also Crewe et al, 2014). Predictably less attention has been paid towards the more diffuse geographies of offender supervision, although Phillips' (2014) recent account explores how the architecture of a probation office potentially impacts on practice.

The specific research focus was also influenced by a pragmatic consideration regarding research ethics and access. One of the potential advantages of using visual methods is its utility as a participatory research approach and we decided that we would invite probation officers in the different countries to collect data (photographic images). At a very early stage of research design we concluded that the images should not include people under supervision because of the ethical issues involved; not least the power dynamics inherent in the supervisory relationship and the potential for breaches of confidentiality if a person could be identified.

\section{Narrowing the Frame}

Traditionally, visual researchers have drawn a distinction between photo-elicitation and photo-documentation methods. While not necessarily mutually exclusive, the former typically uses photos as visual prompts as a means to elicit discussion; the latter involves a systematic production of photos as part of research (Rose, 2007). Auto-elicitation, the approach taken in this study is a photo documentation method (sometimes called photo self-elicitation or photofeedback) which involves asking participants to generate images (Rose, 2007; Stanczak, 2007). Depending on the instructions provided to participants the auto-elicitation method can be broad ranging or more narrowly focused. For example, participants can be asked to 
document aspects of their daily life, choosing any imagery they wish or they can be given very specific instructions to respond to a set of questions.

In any research establishing the boundaries of investigation is important and this is arguably even more so when undertaking comparative research. The question of what we are looking at, and how we are looking at it achieves an echo-chamber effect when multiplied across different contexts. Decisions taken in the context of any research necessarily narrows the frame. Having established that we would seek to engage practitioners in data collection we were then required to think about how we would frame the research to participants. In short, what would we ask them to do? The discussion regarding this aspect of research design was one of the most lively amongst the group. In essence it centred on a debate about the merits or otherwise of very specific instructions to participants (e.g. take a picture of...) versus a more fluid approach whereby within certain parameters practitioners could take pictures of whatever they chose. To a certain extent this debate also reflected different disciplinary backgrounds and epistemological positions within the group ${ }^{2}$.

Since the intention was to compare data across countries, it was ultimately decided that the instructions given to participants would be fairly structured and specific. Thus participants were asked to take photos of specific areas of their probation offices and their work. These were:

- Environment / place in which offender supervision takes place;

- Environment / place in which participants considered they do their most important work;

- Environment / place they would like to spend more time doing their work;

- Anything representing an obstacle to their work;

- Something that would improve the nature of their work;

- Any other images that they thought relevant.

\footnotetext{
2 The research group and authors of this paper comprised two people from a psychology background and five from a social science or socio-legal background.
} 
Even within this degree of structure there was some flexibility. For example asking people to take pictures of something that represents an obstacle to their work or something which would improve the nature of their work requires a degree of interpretation. We also included a final invitation for participants to take any other images that they considered relevant.

\section{Ethics and Access}

Access mechanisms and procedures for ethical approval varied by country. Following a common research design and using shared research instruments (participant information sheets and consent forms), each individual researcher negotiated access in their own country. The variations in the process and the extent to which local knowledge is required provide an indication of some of the complexities involved in comparative research. In some instances ethical approval was required through an institution (i.e. university research ethics committee). Access to research participants (probation workers) was negotiated at different levels in different countries. In some cases this was negotiated at service manager level, whilst in others permission was required at ministerial level.

\section{Research Sample}

After receiving the necessary approvals, participants were drawn from existing networks and/ or through liaison with the relevant services. Recruitment to the project was affected by local contexts including the overall service size. In some countries there was ongoing restructuring, in others budget cuts were resulting in redundancies. The final sample included 14 probation officers; with 2-4 per country. This small convenience sample is by no means representative either within or across countries. This sampling method was chosen for some of the practical reasons already referred to (i.e. access and resources) and as a means to test the utility of a visual research approach in a comparative context. The number of participants from each country varied as did the numbers of photographs produced (see Table 1). Participants were heterogonous with respect to current employment status (practitioner, manager), primary vocation, gender and years of practice experience. 
Table 1: Number of participants by country and the number of photographs collected

\begin{tabular}{|l|l|l|l|l|l|l|}
\hline & \multicolumn{3}{|l|}{$\begin{array}{l}\text { Number of } \\
\text { Country }\end{array}$} & \multicolumn{4}{|l|}{$\begin{array}{l}\text { Total } \\
\text { photographs } \\
\text { by participant }\end{array}$} & $\begin{array}{l}\text { number } \\
\text { of } \\
\text { photographs }\end{array}$ \\
\hline Belgium & 2 & 8 & 11 & & & 19 \\
\hline Croatia & 3 & 12 & 18 & 16 & & 46 \\
\hline Netherlands & 4 & 6 & 23 & 83 & 149 & 261 \\
\hline Northern Ireland & 3 & 12 & 24 & 6 & & 42 \\
\hline England & 2 & 7 & 14 & & & 21 \\
\hline
\end{tabular}

\section{Procedure}

Prospective participants were contacted by researchers and provided with a Participant Information Sheet and Consent Form outlining the aims and objectives of the study and the procedures for consent. In line with the comparative dimension of the research, identical information sheets and consent forms were used. Leaflets were translated into each participating country's official language (Croatian, Dutch and English) ${ }^{3}$ and then distributed to participants who read it and signed a consent form if they were willing to participate ${ }^{4}$.

The consent form outlined the parameters of confidentiality and copyright of the images generated (which is shared between the image producer and the researcher). It also specified that no images should be taken of service users and that if an image was taken of another identifiable person (e.g. a colleague) that consent should be sought from this person. In the information sheet provided, participants were specifically asked to take photos of aspects of the probation environment and work in categories outlined previously. There were no instructions provided as to the

\footnotetext{
${ }^{3}$ The challenges of comparative research were already evident when we found that some terms could not be directly translated. In such instances country equivalents were used (e.g. community sanction and supervision).

${ }^{4}$ This applied in all countries except Belgium where verbal instructions were used instead.
} 
number of photos that participants should take. Participants were also asked to provide a written explanation for the photos they had taken, and to either send photos via e-mail to the researcher or to upload them into a shared folder created for this purpose. In some cases and where possible, follow-up interviews were conducted in which respondents answered questions about their experience of taking part in the research and provided further information on the pictures they had generated.

\section{Data analysis}

The participant-generated photographs were uploaded to a shared folder with separate files for each country. Photos were organised by individual participant and assigned a country code and participant number ${ }^{5}$. A sample overview was also created for each country cataloguing the number of participants, photos and any descriptors. The first stage of data analysis was conducted collectively and involved researchers presenting an overview of their sample. This literally entailed looking through all of the photos and associated commentaries from each country. Having undertaken this initial inventory, we then attempted to group all of the photos according to the instructions we had provided (i.e. environment in which supervision takes place, place where most work is undertaken etc.). However, it quickly became apparent that many of the photographs could not be categorised on this basis. In some instances this was because it was unclear in which category the photo belonged; in other cases photos could be assigned to multiple categories.

Having concluded an overall survey of the data we therefore decided to reorganise the material into more literal and prosaic categories that reflected the content of the images. This led to the establishment of ten new categories, which were:

1. The building and its environs;

2. Reception/waiting area;

3. Explicit messages to offenders (leaflets, signage etc.);

4. Security and control measures;

5. Meeting/interview rooms;

6. Personal workspace;

7. Places to meet colleagues in the building;

\footnotetext{
${ }^{5}$ For example NED01 denotes Netherlands, Participant 1.
} 
8. Community service;

9. Places to meet clients outside the building;

10. Other

This second stage involved further content and thematic analysis (Vince and Warren, 2012) and a specific consideration of the utility of the method in a comparative context. The findings from this analysis are discussed in the next section.

\section{Was the method feasible?}

In response to this question, we would give a qualified 'yes'. On the one hand, our pilot study generated a large collection of photographs: a total of 389 images and a range of 6 (minimum) to 149 (maximum) per participant. On the other hand, not everyone we invited to participate did so, and we do not know why some chose not to. It is possible that the task could have been perceived as too onerous, complicated or technically challenging, but we are unable to know with any degree of certainty because we were keen not to generate perceptions of undue pressure on individuals by enquiring about their non-participation. It was however very clear that those who did opt to participate were keen and interested, and enjoyed the challenge we had set. All of the images were digital, generated via participants' own mobile devices (cameras and phones), and participants did not report any practical or technical difficulties. We therefore suspect that those who did not participate were deterred not by the task itself, but more likely by other pressures on their time.

Our other key finding in relation to the feasibility of the method related to the variable degrees to which participants stuck to the structure we gave them, which was to produce images across a number of specified themes (see above). Regardless of the number of images they had produced, it was not always clear to us whether participants had attempted to capture or address all of the themes we had specified in our written information, or just some of them. Furthermore, some images appeared to represent more than one thing (for example, see Image 1 and the text supplied by the participant, below). 
Image 1: "My desk - an obstacle to work in lots of ways, although also a place where a large part of the 'work' takes place. Systems feel a hindrance, laboured and outdated" (England).

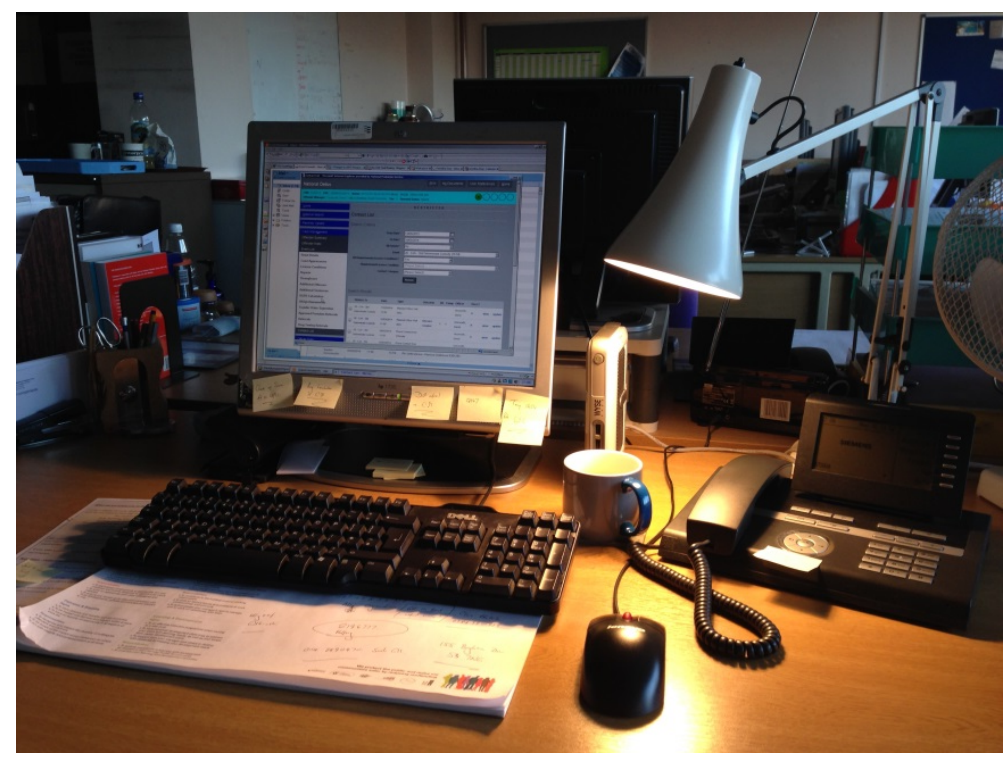

These issues presented us with potential classification and analytical problems, and meant that we could not, with any confidence, group all the images according to our original themes. It also raised questions about the extent to which participants had understood our 'instructions', found them unhelpfully constraining, forgotten them, or simply chosen to 'do their own thing'. Had we been under- or over-specific in our instructions to participants? Or were we simply encountering individual differences which we could not - and perhaps should not try to - iron out in such a project? The variable approaches (and differential productivity) of individual participants was thus interesting, but potentially problematic in terms of direct comparison within our initial framework.

We were able to explore these issues in our informal 'debriefing' interviews with some of the participants, and these provided useful insights. For example, one of the English participants explained that whilst he had largely followed our instructions (i.e. taking care to produce at least one image to correspond with each of our themes), he had not included an image of 'something that would improve the nature of your work' because his ideas in this regard were, he felt, difficult to capture 
visually: such as having more hours in the day; or a better functioning computer system. Although some other participants had experimented with capturing such 'intangibles' (see Image 2 below), not everyone had gone down this more creative route.

Image 2: "Empty name tag at the probation office door: there are not enough of us (officers)" (Croatia)

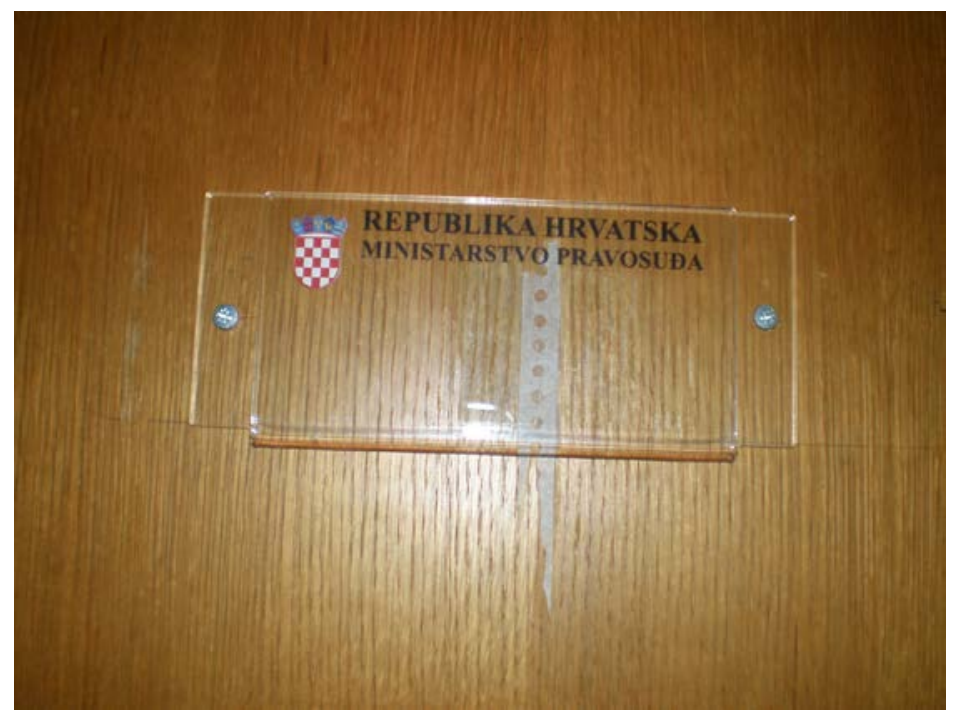

Other participants reported that they had not really paid attention to the instructions, mostly due to enthusiasm for trying to visually capture their work. It thus became clear that gathering data through the method of photo-voice or autoelicitation requires interviewing of the participant afterwards to explore their approach to the task. To know the intentions of participants - that is, knowing what they were seeking to capture or communicate through their images - one needs words - and preferably a narrative account - to supplement them.

\section{What were the strengths of the method?}

A clear strength of the method was its potential to generate a large amount of data very quickly, with no direct costs: as noted above, our 14 participants produced almost 400 images using their own digital devices. Setting aside for a moment the 
challenges this quantity of images created for the purposes of analysis (explored further below), this was - in quantitative terms at least - a preliminary indicator of efficiency in terms of resources.

Another strength of the method was - somewhat paradoxically - also a potential problem (as discussed above), and that was the freedom which it conferred on participants: freedom to make choices about and generate their own images; to exercise their creativity; to provide an account and, ultimately to be genuine cocreators in the research project. Whilst this sense of 'empowerment' may sound trivial, it has to be understood in context: several of our participants (in Belgium, England and Northern Ireland) were experiencing turbulent working conditions, with restructuring and in some cases redundancies about to impact on their professional lives.

Finally, we were struck by the power of the images in our collection to evoke an atmosphere, or emotions, that might be difficult to convey only in words or might evade research questions posed in an interview setting. For example, many of the pictures conveyed humour (see Image 3 below); others communicated frustration; others hope or escapism. We did, however, find that the words which accompanied the pictures in our collection were invaluable as a guide to making sense of their meaning to the individuals who produced them - a point we explore further below.

Image 3: "The main probation office - a grey unassuming block complete with ironic signage" (England). 


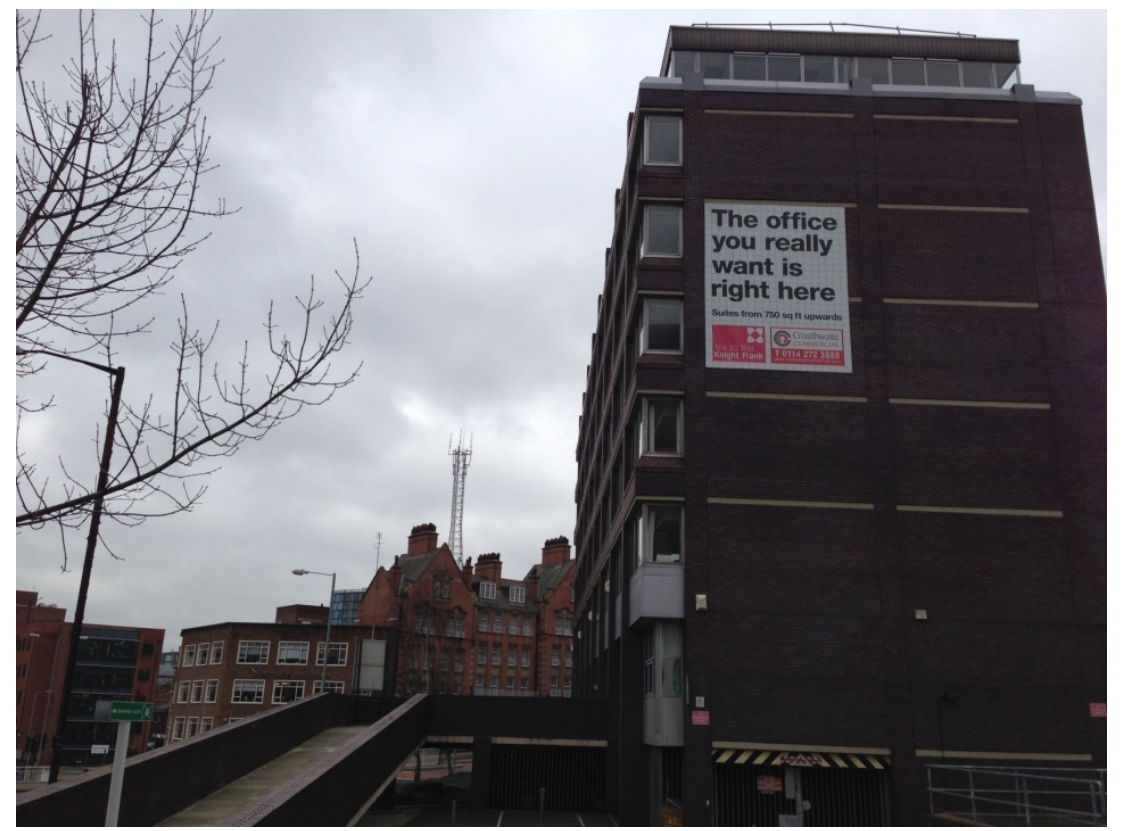

What were the limitations of the method?

An obvious limitation of our collection of images was that it did not contain people.

This however was not a limitation of the method per se, but rather of the method as we had chosen to operationalise it. It would also be a misunderstanding of the method to imply that the absence of people in a photograph necessarily results in an absence of 'humanism', as is clear in Edmund Clark's brilliant photo book of the older prisoners' wing at HM Prison Kingston, entitled Still Life: Killing Time (2007).

'Unpeopled' photos act as an invitation to imagine the lives and dramas that inhabit these physical spaces. Nevertheless, probation is fundamentally relational work and some may feel that there is a limit to the extent to which this 'essence' can be captured in images devoid of people. Once again however, one or two participants found creative ways to represent what they wanted to communicate within the constraints of our instructions: see Image 4 below for an example of this.

Image 4: “Probation officers' hands. The biggest hope and strength of [the] probation office - competent and educated professionals" (Croatia). 


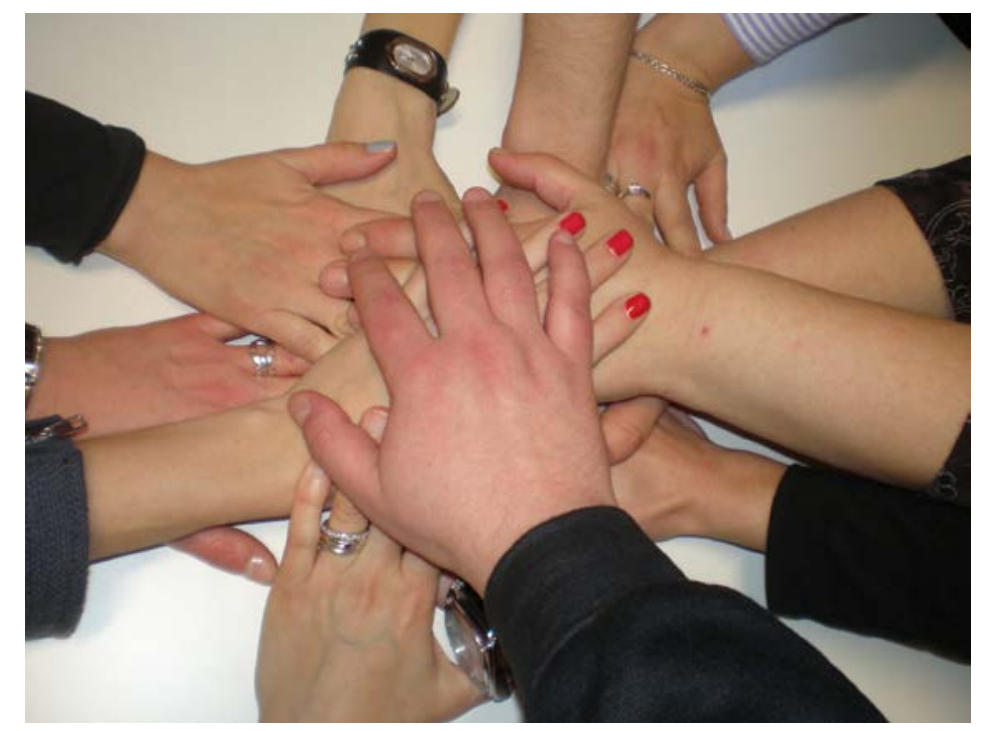

From our perspective, the principal limitation of the method centred on the challenge of interpretation and analysis: in particular, making sense of the images our participants had generated. As noted above, in order to assist us with this, we had asked participants to supply us with some brief text alongside each of their images, and to a large degree, this was helpful. Indeed, we might argue that it was indispensable. For example, a Dutch participant included the following text alongside an image of an open-plan office space:

"The actual working rooms. Large rooms that are too big. A chicken coop. I hate it to work there. Often there is a radio playing. It is far too restless. I feel out of place here."

This text expresses emotions that could not be read into the image in their absence. However, the text supplied by participants did not always help us to access their meanings: for example, the text supplied with the photograph below (Image 5) did not actually aid our understanding of the image ${ }^{6}$. It appears therefore that photovoice or an auto-elicitation method should ideally be supplemented by debriefing interviews with participants.

\footnotetext{
${ }^{6}$ Following an oral presentation of our findings at the European Society of Criminology conference in September 2014, a delegate commented that this image is of a 'Magic 8 Ball': a fortune-telling device designed to 'answer' yes/no questions. See: http://en.wikipedia.org/wiki/Magic 8-Ball (with thanks to Jane Dominey for this observation).
} 
Image 5: "Something that would improve my work" (Northern Ireland).

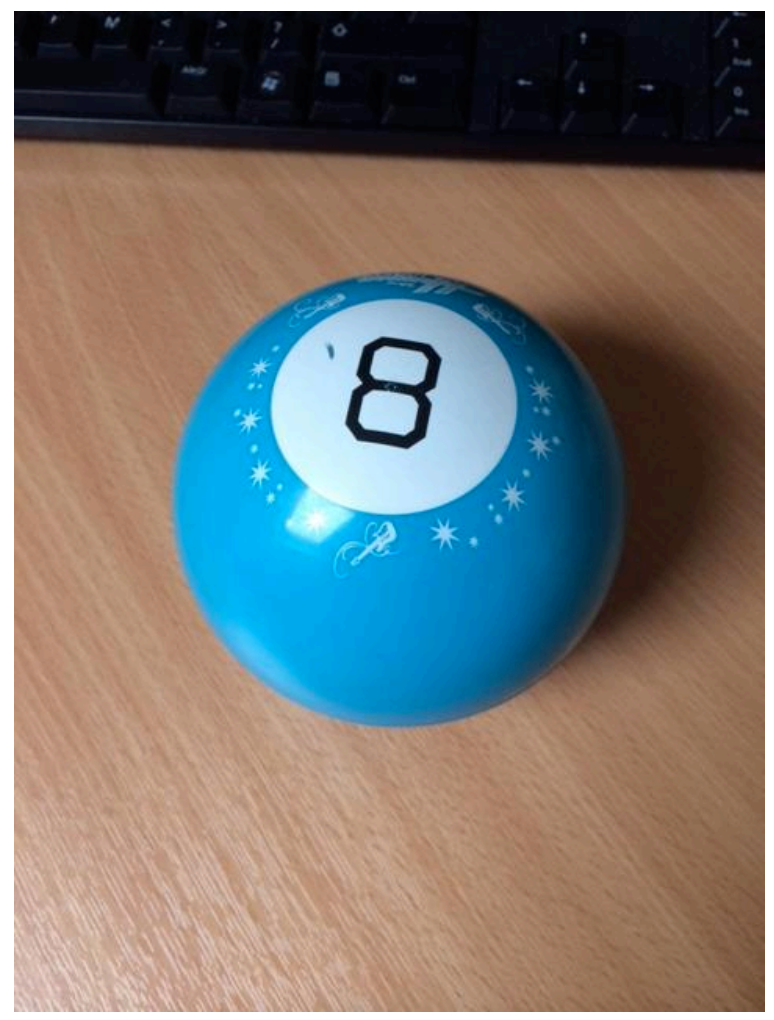

Our data, then, exposed some limitations of the method. Among these were the risks of misinterpretation of images framed and captured by someone else, and the related problem of comparative analysis, explored further below.

What can we learn from visual methods about the geographies and spaces of probation practice?

Having come to the realisation that we would not be able to classify the images according to our original themes, as noted above we ultimately sorted them into more literal categories. We then spent some time looking at each group of photographs (which were printed and displayed on a row of tables) and verbalising our initial impressions, in an effort to achieve a 'collaborative analysis' (Kanstrup 2002). Examining the images in these categories as a group, we were immediately struck by some prominent similarities between contexts, which included workspaces 
and meeting rooms that, despite being in different countries, were often difficult to 'locate' or tell apart, or to differentiate from those in allied occupations such as social work or general medical practice.

We also noted some quite prominent differences between contexts: for example, we found probation offices housed in very different types and sizes of buildings - even within the same country - ranging from tower blocks to small high-street offices. Furthermore, among the images of buildings and doorways housing probation offices, there were differences in the clarity and prominence of their labels and, more generally, their visibility - both to those compelled to visit them and to the general public. Shah (2015) has referred to this as the 'linguistic landscape' in her study of an American parole office. For example, the images below of the exterior of Croation probation buildings making precisely this point.

Image 6: Entrance to building where probation office is located (Croatia)

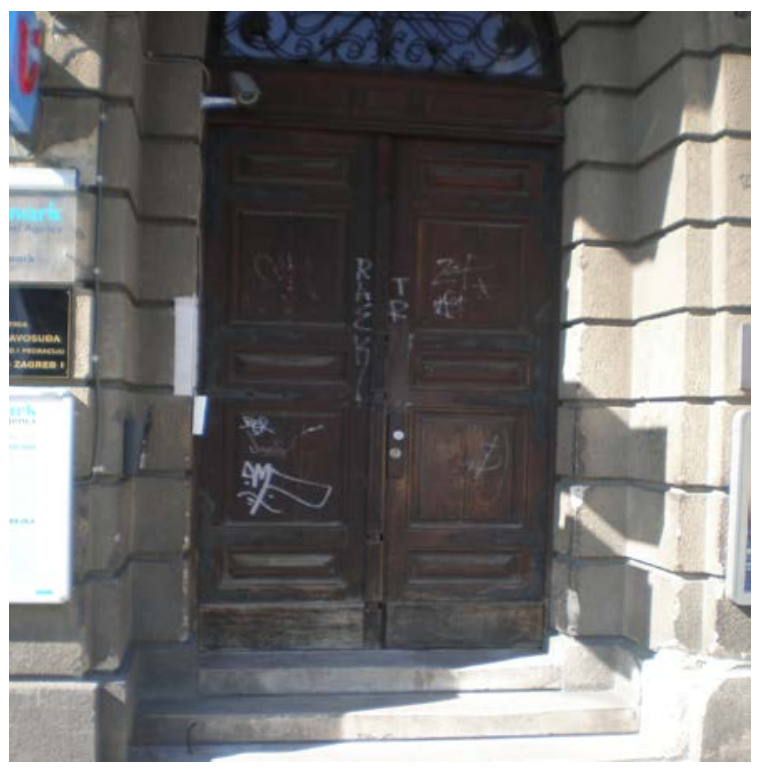

'It looks more like a ruin than a judicial body' 


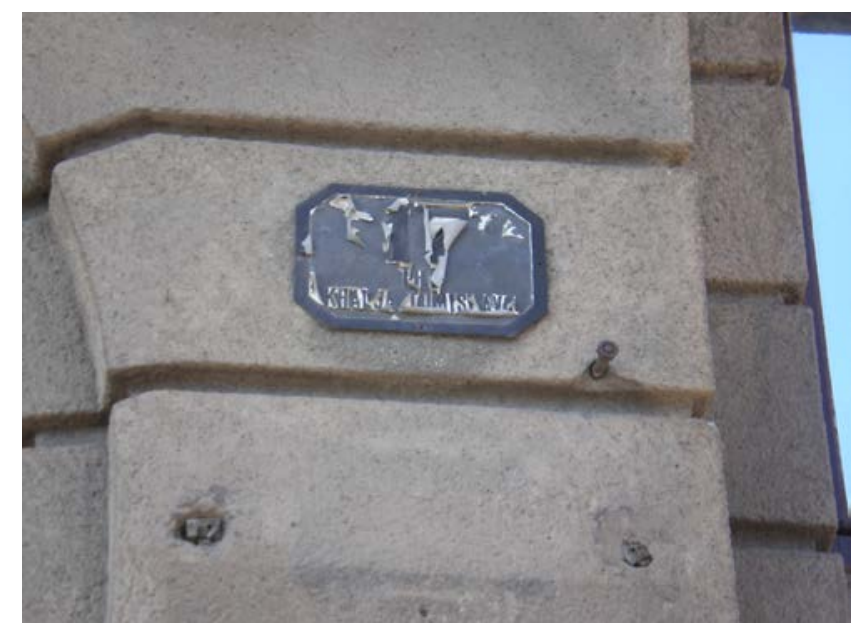

'The street number and addressed is so ruined, that clients often miss it. They then call us to see where it is located.'

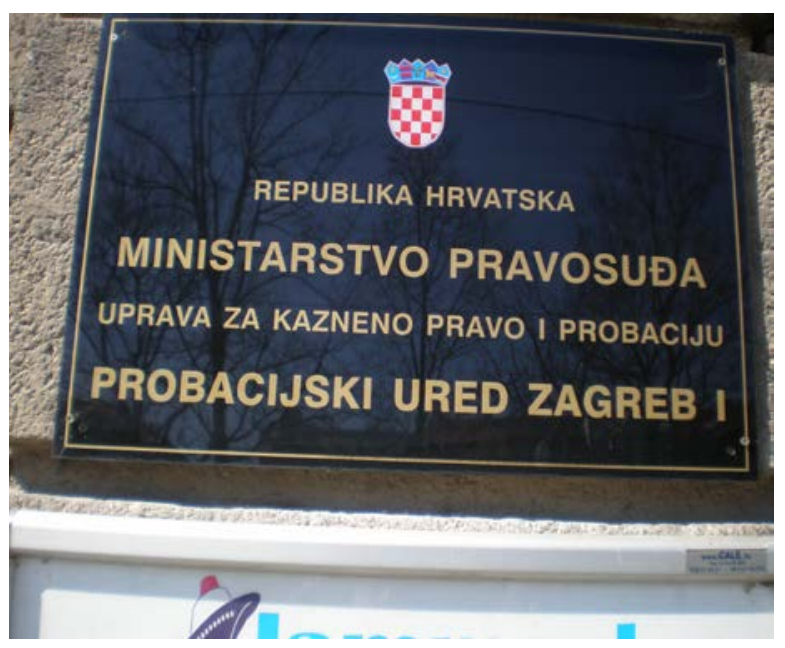

'Our only sign of recognition'

The collection of images of buildings and reception areas also drew to our attention to a distinction between probation offices occupying their own premises, and those which were co-located with other services. We also noted differences in the (apparent) resourcing of probation in different countries, reflected in a variety of our categories, from reception and waiting areas to interview rooms and staffroom areas, which looked more or less 'plush' or comfortable.

\section{Image 7: Interview rooms in 4 countries}



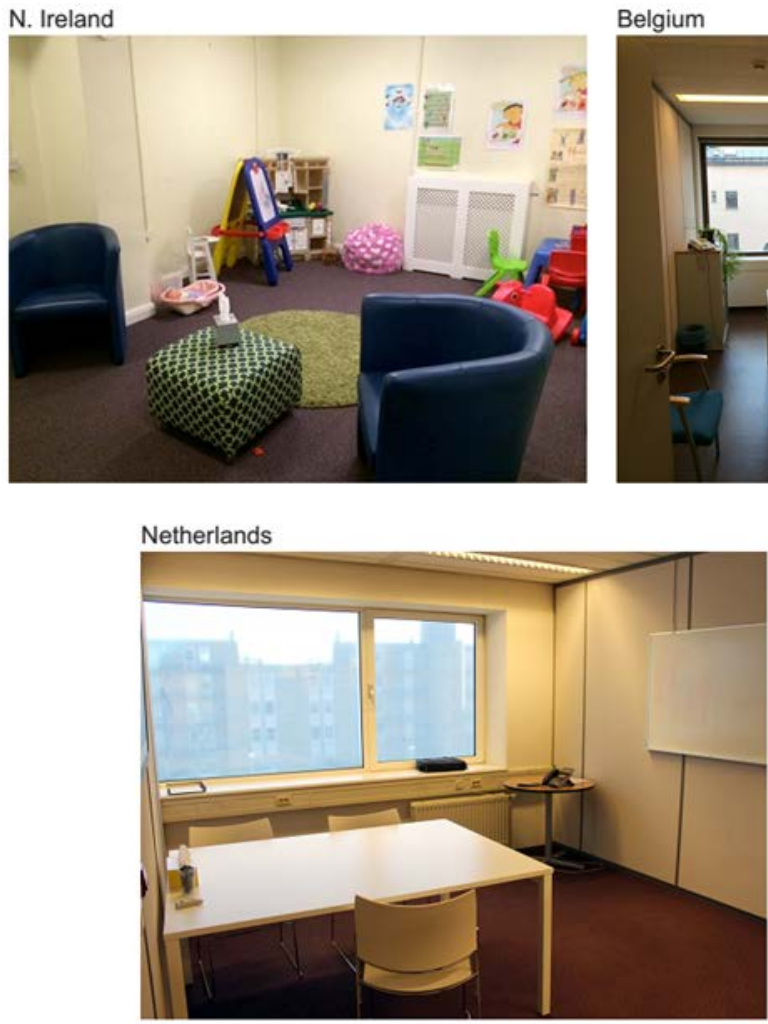
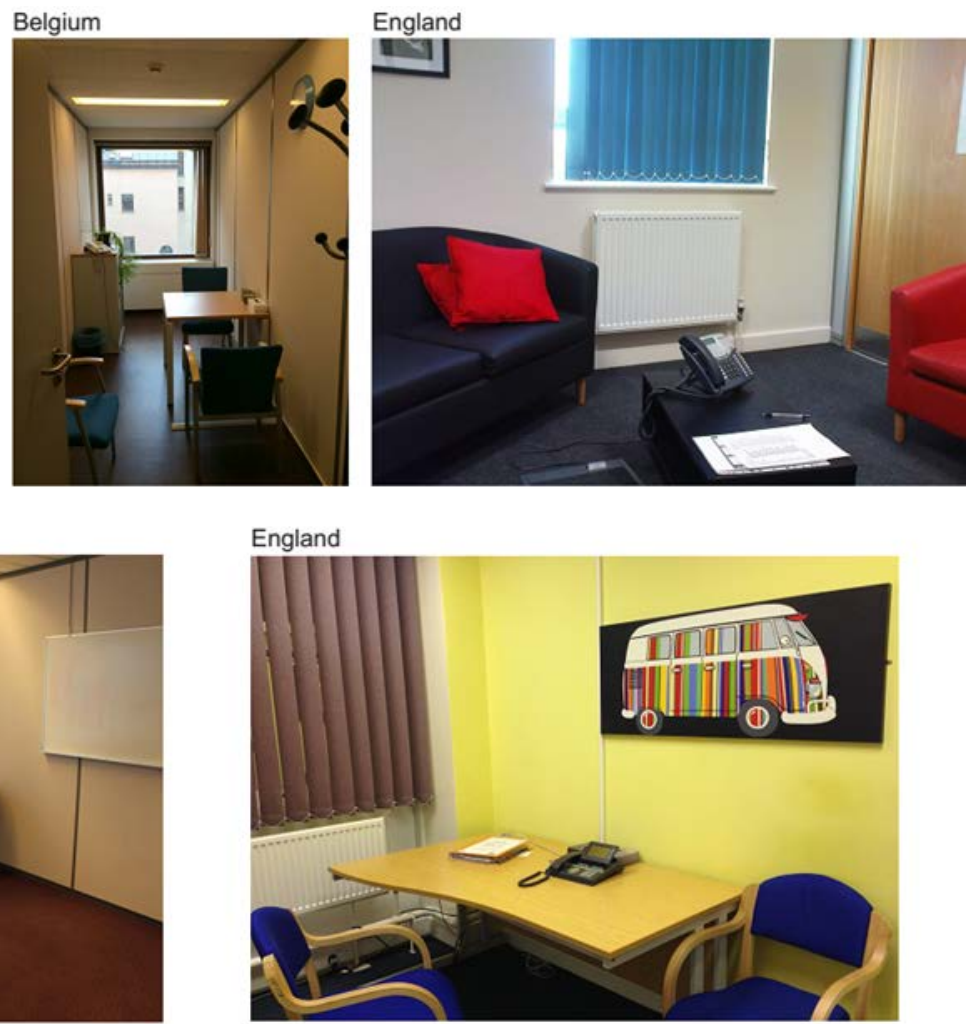

However, we also came to realise, through expressing our own reactions to the images verbally, that there was no single 'standard' against which they could be compared: our own feelings and interpretations of the images in front of us were, to an extent, affected by the cultural lenses we each brought to the process of analysis. These lenses were shaped by our particular (national) experiences of probation spaces, but also our broader, normative assumptions about what furniture, spaces etc. in such a context ought to look like. For example, the many images of waiting areas - whilst in many ways very similar to one another - provoked different reactions in terms of what looked 'normal', or 'more comfortable', or 'more austere'. Thus, to the UK researchers, the furnishings in the Dutch probation offices looked rather luxurious, whilst in Croatia they appeared drab and sparse. Similarly, images of a high-rise office block housing a mix of private businesses and a probation office met with surprise among the researchers from countries in which probation offices tend not to be shared with private organisations (see Image 8). Part of the value of our verbal exchange of initial impressions was thus in exposing the cultural assumptions each of us brought to bear on his or her preliminary analysis of the 
images, but also to alert us (again) to the difficulties inherent in comparative research.

Image 8: "Business tower: building in which probation office is located" (Croatia).

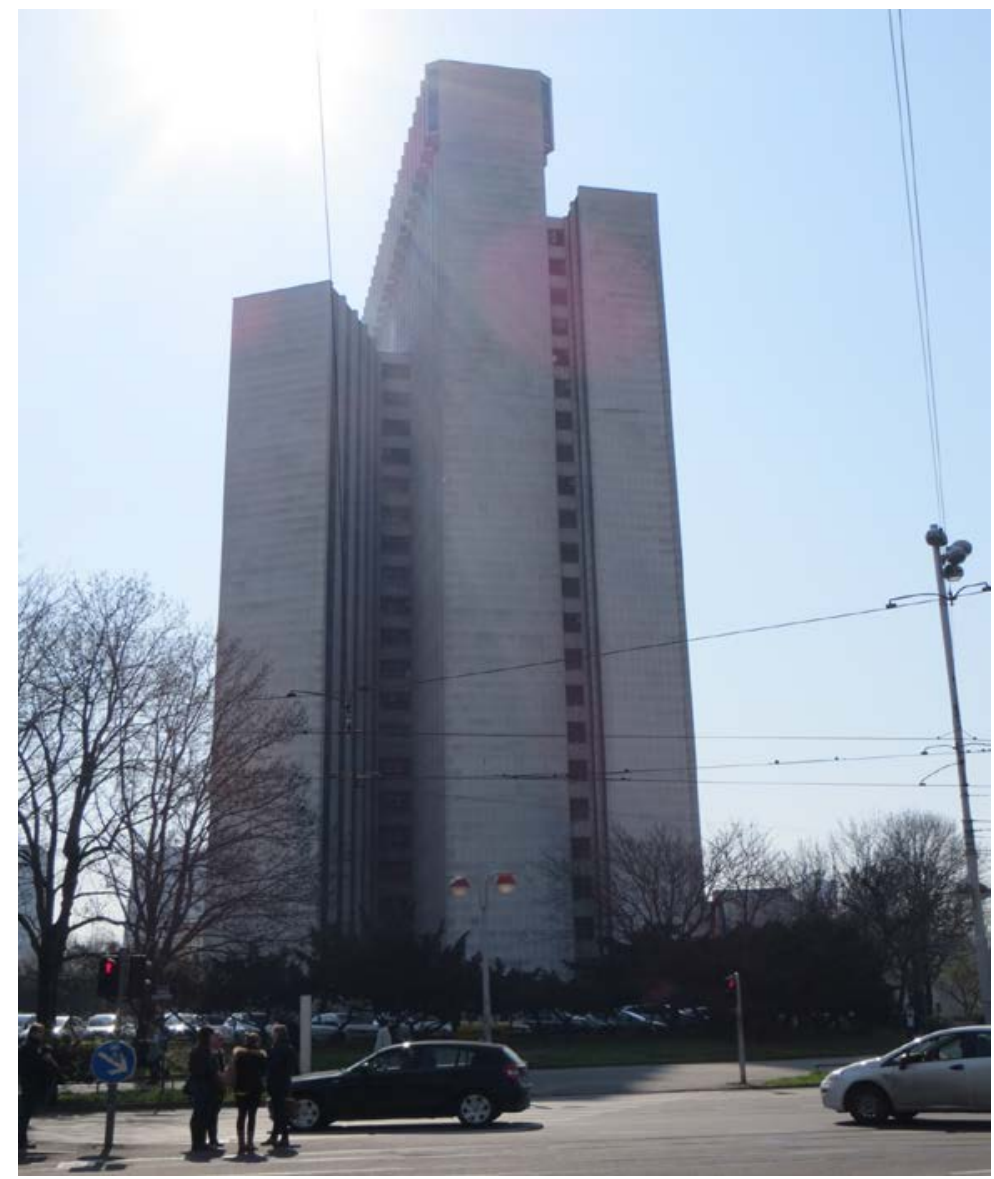

The rudimentary classification system we devised exposed the fact that the majority of our participants had supplied images of both 'frontstage' and 'backstage' social spaces (Goffman 1969; Phillips 2014). Thus, we had lots of images representing areas that clients of probation services would themselves encounter, and in which practitioners and clients would interact, such as the outsides of buildings; reception and waiting areas; and rooms designated for meetings with clients - all 'frontstage' areas. But there were also 'backstage' pictures - of staff offices and kitchens; meeting rooms and case file storage; and even one or two home offices.

We also noted the inclusion of quite a number of images taken in locations away from probation offices. These included a couple of pictures of clients' homes, and 
several taken in the local vicinity of workplaces, which together (and with their supplementary text) suggested a desire to escape the office-based location - and mostly interior world - of probation work. To an extent, these images reflected our request for participants to think about places or spaces in which they would like to spend more of their working time. An example of this is Image 9 of a café where the participant reported having met with a client. The participant emphasized the advantages of meeting the client in a social context but also remarked on the disturbances due to friends who came by.

Image 9: "Location outside probation office to meet the client" (the Netherlands)

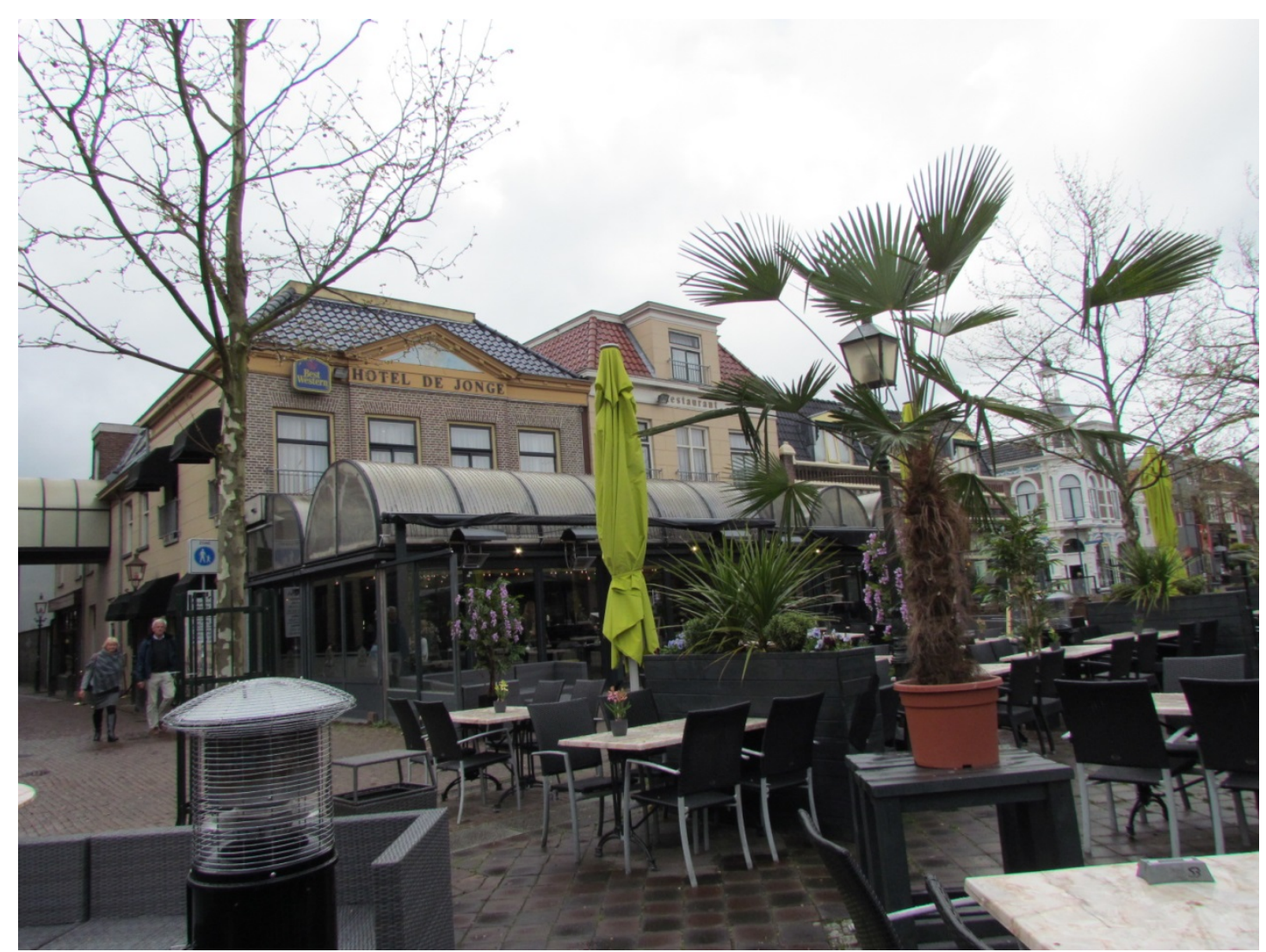

\section{Discussion}


Photographs are increasingly used in social research. Many photographs that are analysed by cultural criminologists are produced by professionals or, at the least, are created for formal research purposes by researchers. Yet, as Carrabine (2012) points out, photography has been democratized by digital technology. Compelling photography can be produced with minimal, or no, skill or understanding of the genre. Consequently, the use of photography as a collaborative research method is now possible, though not unproblematic. The analysis of photographs centres on debates about objectivity/ subjectivity, meaning and the extent to which encountering photos elicits emotional reactions. In other words, it is about 'the relationship between photographer, photographic subject and the larger orbits of meaning they both occupy' (Ferrell and Van de Voorde, 2010:41). Consequently, the extent to which it is possible to analyse work practices through amateur photographs, analysed democratically, remains contested.

In this article, we have discussed the pictures taken by the respondents of the physical environments of probation work and this includes photographs of the interior of probation offices and the artefacts of the job (security glass, notices on walls, waiting rooms, interview rooms, computers and, in some cases, specialised clothing and equipment) as well as the exteriors of buildings and their surroundings. In addition to exploring the utility of democratized photography as a method for researching offender supervision, we have also explored the extent to which photography can be used to overcome textual barriers in comparative criminology. While one feels, instinctively, that the use of visual images must somehow aid our understanding of other cultures, there is very little literature on how or why this might be so.

Furthermore, we might wonder what the comparative analysis of offender supervision is good for. How are we to understand 'the folkways of the field' (Garland, 2001: 24) in other jurisdictions? Comparing offender supervision practices for different European jurisdictions raises some interesting issues for cross-national policy and practice analysis (Beyens and McNeill, 2013). Despite globalising trends, the specific configurations of contemporary social, cultural, historical and political conditions in different jurisdictions are highly variable and directly or indirectly 
influence penal policy and practice. Or as Harris puts it: "What probation "is" cannot be unyoked from the time and place in which it operates or from the political, cultural and historical "baggage" it brings with it" (Harris, 1995: 66).

However, and although the literature is emerging, a robust framework for comparative analysis (including visual analysis in comparative research) is not yet available and still needs to be developed (Nelken, 2009). But the fact that there is currently no framework may not be the biggest challenge. The challenge of understanding the penal practices in other jurisdictions poses more problems, as for instance probation practices are highly dependent on context related elements and any attempt to isolate elements without interpreting the broader context may give rise to misunderstandings (Canton, 2009). Nelken adds that it is not enough to look at what others do or say they do (echoing Cohen's (1985) distinction between the practice and the story), but it 'requires understanding and interpreting what those in other places are actually trying to do' (2009: 291, emphasis in original). Moreover, we need to acknowledge that learning from what others do is never straightforward. But this is easier said than done. It is inevitable that our perception of offender supervision and probation practice will be coloured, to a large degree, by our own cultural starting points, which as previously mentioned includes experiences in the probation field both as practitioners and researchers. These starting points can be conceived as conferring an advantage, in that we know something of the field, and therefore may be trustworthy guides. Or it may be the opposite, in that we bring along our own biases and do not sufficiently heed the landscape assuming what we already know it. Certainly it emphasises the need for reflexivity throughout the endeavour (Lumsden and Winter, 2014).

\section{What did we learn about the use of this methodology?}

Having piloted a method involving comparative analysis across a number of countries we conclude with some reflections on what we learnt about the method and its potential to contribute to comparative research on offender supervision.

Our experience is that there are important choices to be made by researchers at the research design stage, concerning the degree of structure they wish to impose on 
participants. These choices are likely to have significant implications for the range and types of images participants produce. There are significant individual differences between participants in terms of how they approach and undertake the photography task, including their productivity and creativity. Researchers embarking on such a project therefore need to be aware that there may be limits to the degree of standardisation it is possible to achieve between participants.

It is important to bear in mind that a small-scale pilot study such as this will not generate a representative sample of images, even within a single jurisdiction. In order to achieve this, a much large sample of participants would be needed. Furthermore, analysing visual images is challenging. When seeking to analyse images captured by someone else, there is no guarantee of really understanding what we are seeing. The task becomes even more challenging when it has a comparative dimension. We found that when comparing images taken in different countries, it was important to have a knowledgeable and trustworthy local guide to provide essential context to avoid the dangers of what Nelken has coined 'ethnocentrism and relativism' $(2009,2012)$. Ethnocentrism being described as 'assuming that what we do, our way of thinking about and responding to crime, is universally shared or, at least, that it would be right for everyone else' (2009:291). Relativism, by contrast, is the term used for never being able to fully grasp what others are doing. It is the argument that each probation culture has to be understood, interpreted and analysed in its very own terms, questioning the possibility for any outsider to understand a (probation) culture and practice that is not their own.

Words are helpful alongside images, but the addition of words does not always guarantee that we (as researchers) will see exactly what the photographer seeks to capture and convey to us. Creating opportunities for discussion of the images and their meanings from the perspectives of participants is a very valuable aspect of this method. Furthermore, images generated by a project like this - however small - can be utilised in 'photo-elicitation' research. In other words, they can act as a starting point for discussion among a range of potential audiences about the empirical realities and/or the normative aspects of offender supervision: how it is, and how it ought to be. 
We have concluded that photography is a useful method for capturing comparative data about the places and spaces in which probation work happens - and, potentially, how practitioners feel about both their work and where it happens. Based on our experience of piloting the method, we are confident that it has the potential to raise new questions for comparative research. We aim to explore some of these questions in a subsequent publication. In our pilot project we have only begun to explore the potential of visual methods in comparative research. Like any other method, it has its limitations. We think however that there is potential for mixed-methods research to combine the strengths of photo-voice alongside methods such as observation and/or practitioner diaries, which are both discussed in other contributions to this volume. 


\section{References}

Bagnoli, A. (2009) 'Beyond the Standard Interview: The Use of Graphic Elicitation and Arts-based Methods', Qualitative Research, special issue, 9,5: 547-570.

Bagnoli, A. and Clark, A. (2010) 'Focus Groups with Young People: A Participatory Approach to Research Planning', Journal of Youth Studies, 13(1), 101-119.

Beyens, K. \& McNeill, F. (2013) 'Conclusion: Studying mass supervision comparatively.' In: F. McNeill \& K. Beyens (Eds.) Offender Supervision in Europe. Hampshire: Palgrave Macmillan (pp. 155-169).

Brown, M. \& Carrabine, E. (forthcoming) The Routledge International Handbook of Visual Criminology. Abingdon: Routledge.

Canton, R. (2009) 'Taking probation abroad', European Journal of Probation, 1,1, 6678.

Carrabine, E. (2012) 'Just images: aesthetics, ethics and visual criminology', British Journal of Criminology, 52,2,463-89.

Cohen, S. (1985) Visions of social control: crime, punishment and classification. Cambridge Polity Press.

Clark, E. (2007) Still Life: Killing Time, Stockport, Dewi Lewis Publishing.

Crewe, B., Warr, J., Bennett, P. \& Smith, A. (2014) 'The emotional geography of prison life.' Theoretical Criminology, 18,1: 56-74

Eisner, E. (2008) 'Art and Knowledge', in J.G. Knowles and A.L. Cole (eds) Handbook of the Arts in Qualitative Research: Perspectives, Methodologies, Examples, and Issues, pp. 3-12, London: Sage.

Ferrell, J. \& Van de Voorde, C. (2010) 'The decisive moment: documentary photography and cultural criminology' in K.J. Hayward \& M. Presdee (eds) Framing crime: cultural criminology and the image, Abingdon, Routledge.

Garland, D. (2001) The Culture of Control: crime and social order in contemporary society. Oxford: Oxford University Press.

Goffman, E. (1969) The Presentation of Self in Everyday Life. London: Allen Lane. Harper, D. (2002) 'Talking about pictures: A case for photo elicitation.' Visual Studies, 17,1: $13-26$

Hayward, K. \& Presdee, M. (2010) Framing Crime. Cultural Criminology and the Image. Abingdon: Routledge. 
Harris, R. (1995) 'Probation round the world: origins and development', in K. Hamai, R. Villé, R. Harris, M. Hough and U. Zvekic (eds.), Probation Round the World: A Comparative Study (pp. 3-24). Abingdon: Routledge.

Kanstrup, A-M. (2002) 'Picture the practice: Using photography to explore use of technology within teachers' work practices', Forum: Qualitative Social Research, 3, 2: Art 17.

Knoblauch, H., Baer, A., Laurier, E., Petschke, S., \& Schnettler, B. (2008) 'Visual Analysis. New Developments in the Interpretative Analysis of Video and Photography.' Forum Qualitative Sozialforschung / Forum: Qualitative Social Research, 9, 3, Art. 14. Available at: http://nbn-resolving.de/urn:nbn:de:0114$\underline{\text { fqs0803148 }}$

Lumsden, K. \& Winter, A. (2014) Reflexivity in Criminological Research. Experiences with the Powerful and the Powerless. Hampshire: Palgrave Macmillan

Moran, D. (2015) Carceral Geography: Spaces and Practices of Incarceration. Surrey: Ashgate

Nelken, D. (2009) 'Comparative criminal justice: beyond ethnocentrism and relativism', European Journal of Criminology, 6, 4, 291-311.

Nelken, D. (2012) 'Comparing criminal justice', in M. Maguire, R. Morgan and R. Reiner (eds.), The Oxford Handbook of Criminology (5th ed.) (pp. 138-158). Oxford: Oxford University Press.

Pakes, F. (2014) Comparative Criminal Justice. (Third Edition). Abingdon: Routledge McNeill, F. and Beyens, K. (2013) Offender Supervision in Europe. Hampshire: Palgrave Macmillan.

Phillips, J. (2014) 'The architecture of a probation office: A reflection of policy and an impact on practice', Probation Journal, 61: 117-131.

Prosser, J. \& Schwartz, D. (1998) 'Photographs within the Sociological Research Process.' In J. Prosser (Ed.) Image-based Research: A Sourcebook for Qualitative Researchers. Falmer Press. London.

Prosser, J. \& Loxley, A. (2008) Introducing Visual Methods. National Centre for Research Methods, NCRM Review Papers, NCRM/010. Available at: http://eprints.ncrm.ac.uk/420/1/MethodsReviewPaperNCRM-010.pdf

Rafter, N. (2014) 'Introduction to special issue on visual culture and the iconography of crime and punishment', Theoretical Criminology, 18, 2, 127-33 
Ray, J.L. \& Smith, A.D. (2012) 'Using photographs to research organizations:

Evidence, considerations and application in a field study.' Organizational Research Methods, 15,2: 288-315

Robinson, G. \& Svensson, K. (2013) 'Practising Offender Supervision.' In: F. McNeill \& K. Beyens (Eds.) Offender Supervision in Europe. Hampshire: Palgrave Macmillan (pp. 97-124).

Robinson, G. (2015 forthcoming) 'The Cinderella Complex: Punishment, society and community sanctions.' Punishment and Society

Rose, G. (2007) Visual Methodologies. An Introduction to the Interpretation of Visual Materials. (2 $2^{\text {nd }}$ Edition). London: Sage

Shah, R. (2015) 'Expanding the community: An exploratory analysis of an American parole office's location and its impact on parolees', British Journal of Criminology, 55, 2: 321-40.

Stanczak, C. (Ed.) (2007) Visual Research Methods. Images, Society and Representation. California: Sage

Vince, R. \& Warren, S. (2012) 'Participatory Visual Methods.' In: C. Cassell \& G. Symon (Eds.) The Practice of Qualitative Organisational Research: Core Methods and Current Challenges. London: Sage 